\title{
Manual de la Ley de Propiedad y Cercado de Florida: Posesión Adversa ${ }^{1}$
}

Michael T. Olexa y Joshua A. Cossey²

\section{Prefacio}

La agricultura y la ganadería, que consta de aproximadamente 19,000 granjas ganaderas, junto con las haciendas de caballos, cultivos de naranja, soya, caña de azúcar, algodón, cacahuate y muchas otras instalaciones agrícolas han tenido un impacto significativo en la economía de Florida. A través de los últimos 25 años, la economía agrícola de Florida ha requerido co-existir con el rápido crecimiento poblacional y comercial en el estado. Por los conflictos entre esos intereses se han desarrollado temas de gran relevancia como los derechos y responsabilidades de los terratenientes colindantes, agricultores y propietarios en general. Debido a la importancia agregada a esas áreas de propiedad real, los aspectos legales del cercado en el estado de Florida, han tomado una importancia significativa.

Este manual esta diseñado para informar al propietario de sus derechos y responsabilidades en relación a sus obligaciones de cercado. Las áreas discutidas incluyen la responsabilidad del propietario para cercar cuando el ganado es mantenido en su propiedad, los derechos de los terratenientes colindantes, las ubicaciones de las cercas, invasiones, líneas fronterizas, derechos de propiedad, contratos, molestias y las responsabilidades del terrateniente hacia las personas que entran en su propiedad.

Este manual deberá proveer una revisión básica de los muchos derechos y responsabilidades que los granjeros y los dueños de las granjas tienen, conforme la ley de propiedad y cercado de Florida. Los lectores pueden consultar este manual, ya que les informa sobre esos derechos y responsabilidades. Sin embargo, deberá ser cuidadoso porque las leyes, reglas administrativas y decisiones de la corte sobre las cuales esta basado este manual, están sujetas a revisión constante, y partes del mismo podrían volverse obsoletas en cualquier momento. Este manual no deberá ser visto como una guía completa de las leyes de propiedad y cercado. Adicionalmente, muchos detalles de las leyes citadas se excluyeron por limitaciones de espacio. Este manual no deberá parecer como un manifiesto de opinión o asesoría legal de los autores en ninguno de los temas legales discutidos en este. Este manual no es un reemplazo del personal de asesoría legal, es solamente una guía para informar al público de los

1. Este es el documento EDIS FE691, una publicación de Food and Resource Economics Department, Florida Cooperative Extension Service, Institute of Food and Agricultural Sciences, University of Florida, Gainesville, FL. Pubicado en Julio 2007. Por favor visite la página electrónica de EDIS en http://edis.ifas.ufl.edu.

2. Michael T. Olexa, Profesor,1 Food and Resource Economics Department, y Director, UF/IFAS Agricultural Law Center, Florida Cooperative Extension Service, Institute of Food and Agricultural Sciences, University of Florida, Gainesville, FL; y Joshua A. Cossey, estudiante de tercer año de leyes, Levin College of Law, University of Florida, Gainesville, FL. La traducción del ingles al español estuvo a cargo de Filiberto Reyes-Villanueva. 
temas relacionados a las leyes de propiedad y cercado de Florida. Por esas razones, el uso de esos materiales por cualquier persona constituye un acuerdo por mantener a los autores, al Instituto de Ciencias Agrícolas y Alimento, al Centro de Ley Agrícola y la Universidad de Florida libres de perjuicios por cualquier demanda de responsabilidad, daños o gastos que cualquier persona pudo haber incurrido, como resultado de la referencia o la confianza de la información contenida en este manual.

\section{Agradecimientos}

Los autores agradecen a Jeffrey R. Dollinger, Esq., Profesor Adjunto de la Facultad de Leyes Levin de la Universidad de Florida y accionista en Scruggs \& Carmichael P. A., en Gainesville, Florida, por su ayuda en la revisión de este manual.

\section{¿Qué es una posesión adversa?}

Diferente a las limitaciones por acuerdos y limitaciones por consentimiento, la posesión adversa no solamente se aplica a las invasiones de los propietarios colindantes sino también a los derechos del propietario de cualquier porción de tierra. La posesión adversa ocurre cuando una persona pierde el titulo de propiedad debido a que otra persona ha ocupado la tierra por un mínimo de siete años, resultando en un traslape de descripciones legales. Además del requerimiento de los siete años, y para ordenar que un individuo se apodere adversamente de la tierra de otro, también deba poseer la tierra abierta, notoria y visiblemente de una manera tal que esta en conflictos con el derecho a la propiedad del dueño. Por tanto, A no puede poseer adversamente la tierra de B si A tiene el permiso de B para estar en su tierra. Además, A debe poseer la tierra continuamente por un periodo de siete años y la posesión debe ser exclusiva para el uso de otros y del propietario. Es importante apuntar que desde que B tiene el titulo legal de la tierra, A debe proveer claramente los requerimientos para la posesión adversa (ver Downing v Bird, 100 So. 2d 57 [Fla. 1958]; 2 Fla. Jur. 2d Posesión Adversa secciones 8-36). Además de esos requerimientos básicos por posesión adversa, la ley de Florida requiere que un posesionario adverso ocupe la tierra al menos por siete años y reúna cada uno de los dos siguientes requerimientos: posesión adversa conforme la excusa del derecho o posesión adversa sin excusa del derecho.

\section{Posesión adversa conforme la excusa del derecho (Est. Florida Sección 95.16)}

Un posesionario adverso puede reclamar la propiedad según el la excusa del derecho si reúne las siguientes dos condiciones:

1. El posesionario adverso debe mostrar que el reclamo del titulo de la tierra esta basado en un documento registrado por escrito (aun si es culpable). El posesionario adverso debe genuinamente creer que el documento sea el correcto reclamo del titulo (ver Bonifay $v$. Dickson, 459 So. 2d 1089 [1st DCA 1984]; 2 Fla. Jur. Posesión Adversa sección 10; Seton v. Swann, 650 So. 2d 35 [Fla.1995]).

2. El posesionario adverso debe mostrar posesión de propiedad de la tierra por un mínimo de siete años, y que ha hecho uno de los siguientes:

- Cultivando o haciendo mejoras.

- Protegiéndola con un encerrado sustancial (usualmente una cerca).

- Si no esta cercada, usando la tierra para abastecer de alimento o de cercado, de madera para la agricultura o el uso ordinario del ocupante.

- Mejorando parcialmente una porción de un reconocido lote o una sola granja, haciendo que la parte no mejorada, si en la costumbre del área, se considero ocupada.

\section{Posesión adversa excusa del derecho (Est. Florida Sección}

\subsection{8)}

Cuando un individuo ocupa continuamente una propiedad por siete años consecutivos, careciendo de cualquier documente legal que apoye un reclamo del titulo de la tierra, él puede establecer una posesión adversa por: el archivo de un retorno con el valuador 
del condado dentro del año que entró a la propiedad

y el pago de todos los impuestos y embargos

preventivos valorados durante la posesión de la

propiedad.

La propiedad es considerada posesionada

solamente si el individuo:

- Cultivó o mejoró la tierra, o

- Protegió el terreno por un cercado sustancial, el cual usualmente es una cerca (ver Mullins $v$.

Culbert, 898 So. 2d 1149 [Fla. 2005]. El

impuesto eficiente para establecer una posesión

adversa o color del titulo (ver Bentz v. McDaniel, 872 So. 2d 978).

\section{Resumen}

Los requerimientos para la posesión adversa son muy estrictos. La persona reclamando la posesión adversa, debe poseer la tierra abierta, notoria y visiblemente, de manera tal que esta en conflicto con el derecho a la propiedad del dueño. Además, esta persona debe tener cualquier clase de derecho sobre el cual base el reclamo del titulo, o la persona debe tener pagado los impuestos de la propiedad sobre la tierra reclamada para ser adversamente posesionada. De nota final, la persona debe poseer la tierra continua y exclusivamente por un periodo al menos de siete años.

\section{Información Adicional}

Circular 1214, Manual de la ley de Propiedad y

Cercado de Florida

http://edis.ifas.ufl.edu/

TOPIC_BOOK_Florida_Fence_and_Property_Law 